\title{
Signo Radiológico: "El lirio caído"
}

\author{
Dres. Samuel Sánchez $C^{(1)}, M$. Carolina Pérez $\mathbf{S}^{(2)}$.
}

1. Radiólogo, Fellow Radiología Infantil Clínica Las Condes, Universidad de Chile.

2. Radióloga Infantil Clínica Las Condes, Corporación Renal Infantil Mater. Santiago - Chile.

\section{Radiology sign: "The drooping lily"}

Abstract: "The drooping lily" sign, also known as "wilting flower," corresponds to an imaginological alteration reported over 40 years ago. Initially described in excretory urography, it represents the appearance of the inferior ureteropelvic renal system with a duplicated collecting system, in which the renal pelvis is horizontal and calices are discreetly directed towards caudal. Despite the current limited use of excretory urography, the drooping lily sign remains valid and of diagnostic use in voiding cystourethrograms (VCUG) (also micturating cystourethrogram (MCUG)), computed tomography urography (CTU) and magnetic resonance urography (MRU).

Keywords: Drooping lily, Duplication of the ureteropelvic system, Urethrocystography.

Resumen: El signo del "lirio caído" ("drooping lily" en la literatura anglosajona), también llamado "flor marchita", corresponde a una alteración imaginológica reportada hace más de 40 años. Inicialmente descrito en pielografía de eliminación, representa el aspecto que adquiere el sistema pieloureteral inferior de un riñón con doble sistema excretor, dado por una pelvis renal de orientación horizontal y cálices que se dirigen discretamente hacia caudal. A pesar de la escasa utilización de la pielografía de eliminación en la actualidad, el signo de lirio caído sigue vigente y resulta de utilidad diagnóstica en uretrocistografía miccional, urografía por tomografía computarizada (UroTC) y urografía por resonancia magnética (UroRM). Palabras clave: Duplicación del sistema pieloureteral, Lirio caído, Uretrocistografía.

Sánchez S, et al. Signo Radiológico: "El lirio caído". Rev Radiol 2013; 19(2): 82-87.

Correspondencia: Dr. Samuel Sánchez C. / samuelsanchezc@yahoo.cl

Trabajo recibido el 14 de marzo de 2013, aceptado para publicación 15 de mayo de 2013.

\section{Análisis Imaginológico}

El signo del lirio caído (Figura 1), fue descrito hace más de 40 años en pielografía de eliminación y corresponde al aspecto que adquiere el sistema pieloureteral inferior en un riñón con doble sistema excretor, dado por una pelvis renal de orientación horizontal y cálices que se dirigen discretamente hacia caudal ${ }^{(1)}$. Con cierta frecuencia, el sistema pieloureteral superior no funcionante, a menudo dilatado y displásico, produce efecto de masa con desplazamiento lateral e inferior del sistema pieloureteral inferior funcionante, en especial de sus cálices de ubicación más cefálica, acentuando la apariencia de lirio caído(2) (Figura 2).

Aunque la pielografía de eliminación ha desaparecido progresivamente de la práctica clínica, este signo sigue visualizándose en imágenes diagnósticas, principalmente en uretrocistografía de niños que presentan reflujo vesicoureteral al sistema inferior de un doble sistema pieloureteral completo. En este caso, el lirio caído está dado por la opacificación del sistema pieloureteral inferior refluyente, que presenta

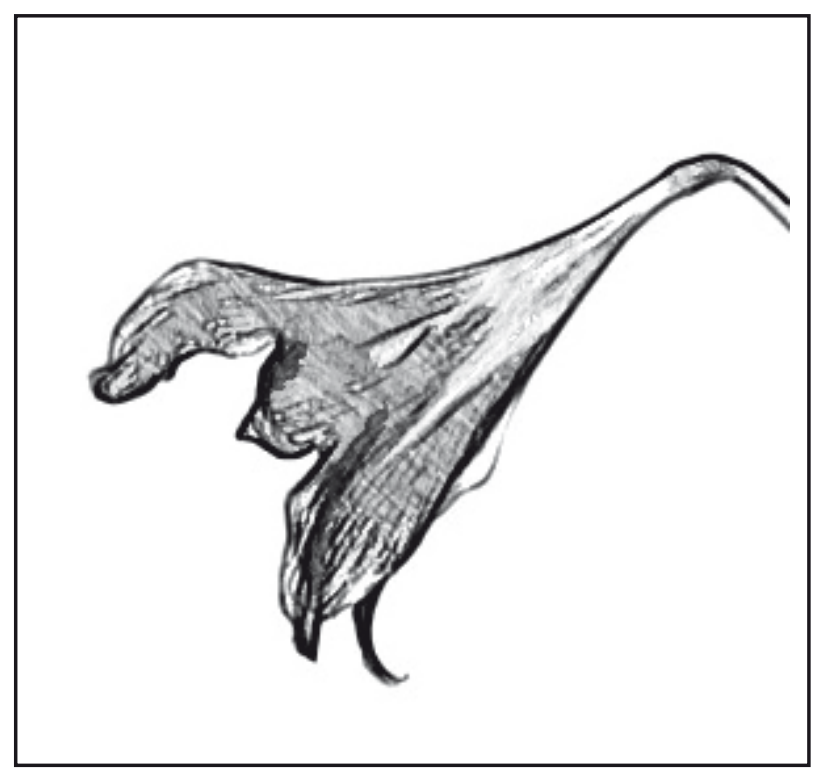

Figura 1. Esquema gráfico de un lirio caído. 

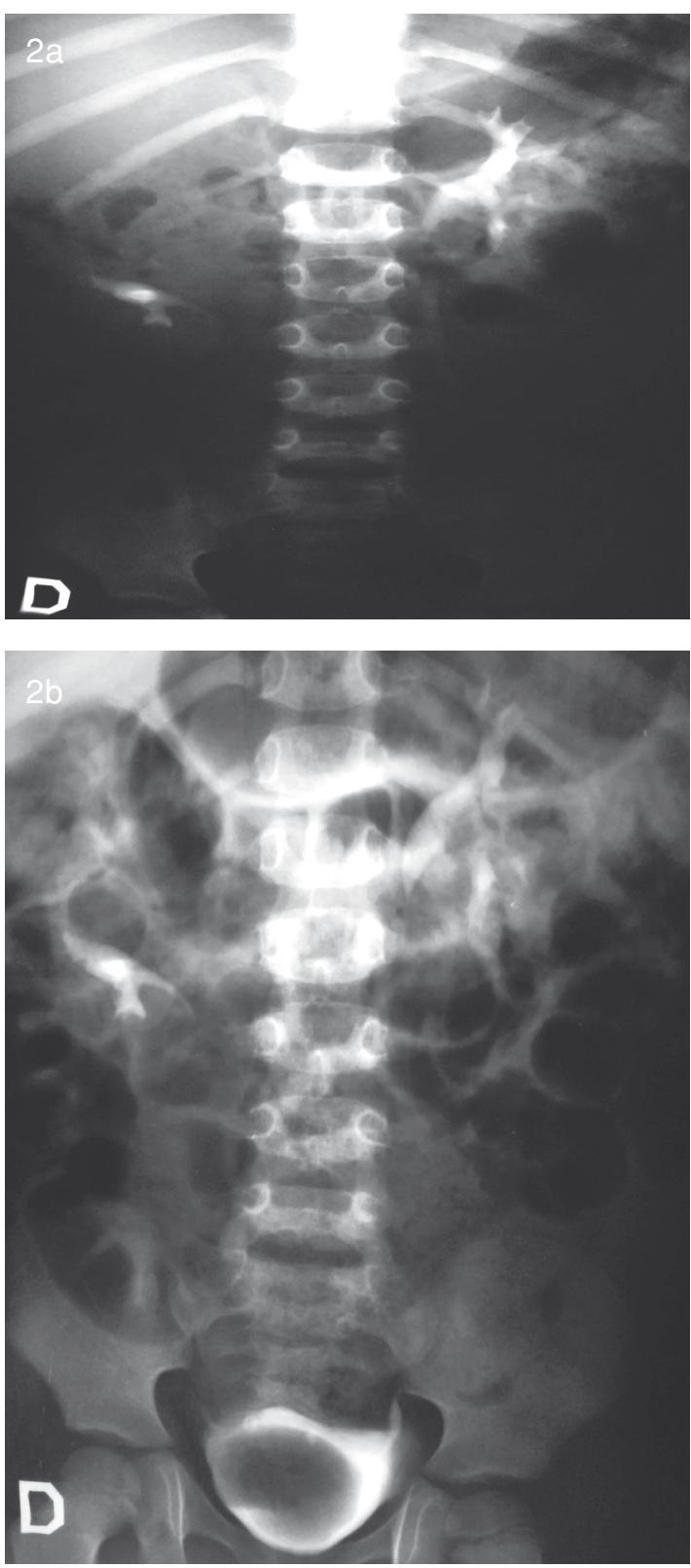

Figura 2a, b. Pielografía de eliminación. a) Etapa de excreción temprana que muestra falta de representación de cálices superiores de riñón derecho sugerente de doble sistema excretor con sistema superior no funcionante, dando la típica apariencia de "Lirio Caído". b) Etapa de excreción avanzada que muestra imagen típica de "Lirio Caído" a derecha con presencia de medio de contraste vesical y defecto de llenado a este nivel compatible con ureterocele.

habitualmente una orientación más horizontal de la pelvis renal, con cálices medios e inferiores, sin representación del grupo caliciario superior (Figura 3). La apariencia de flor marchita es más evidente en la medida que el sistema superior esté más dilatado, especialmente en presencia de ureterocele o uréter ectópico con hidroureteronefrosis secundaria (Figura 4). La visualización de reflujo vesicoureteral con esta configuración debe hacernos plantear el diagnóstico de doble sistema excretor.
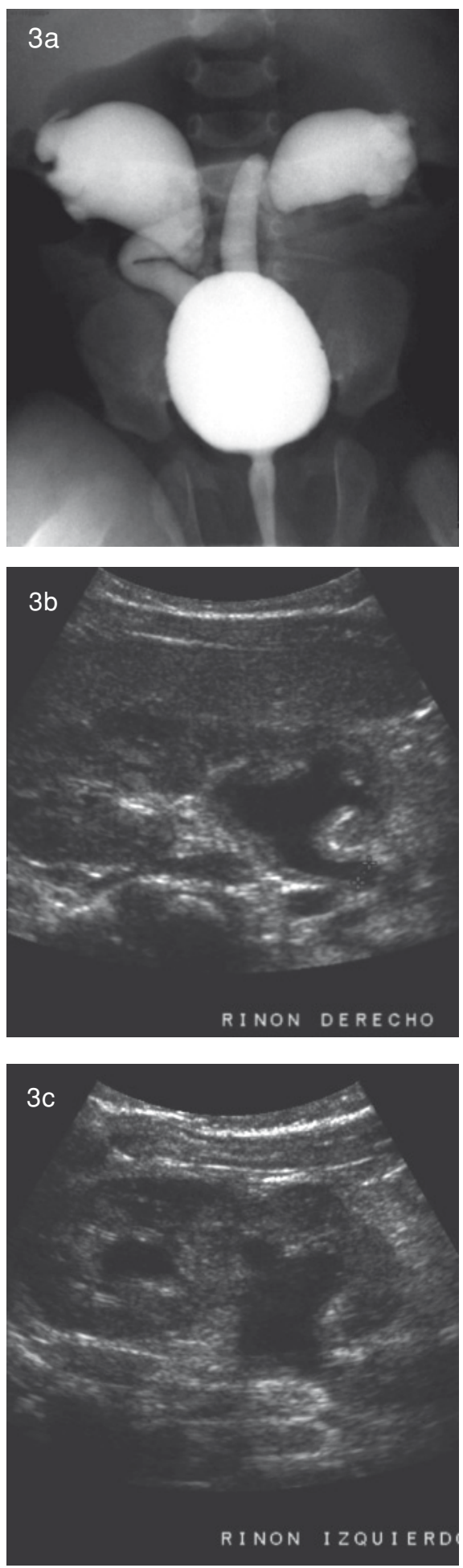

Figura $3 \boldsymbol{a}, \boldsymbol{b}, \boldsymbol{c}$. Paciente con doble sistema pieloureteral completo bilateral y reflujo vesicoureteral a ambos sistemas inferiores. a) Imagen de uretrocistografía en etapa miccional que demuestra reflujo vesicoureteral a sistemas pieloureterales inferiores. Nótese la poca representación de cálices superiores, con pelvis de disposición horizontal, dando la apariencia de "Lirio Caído". b y c) Imágenes de ultrasonido del mismo paciente donde se observa imagen de doble sistema derecho (b) e izquierdo (c), con hidroureteronefrosis de ambos sistemas inferiores y leve dilatación también del sistema superior izquierdo. 

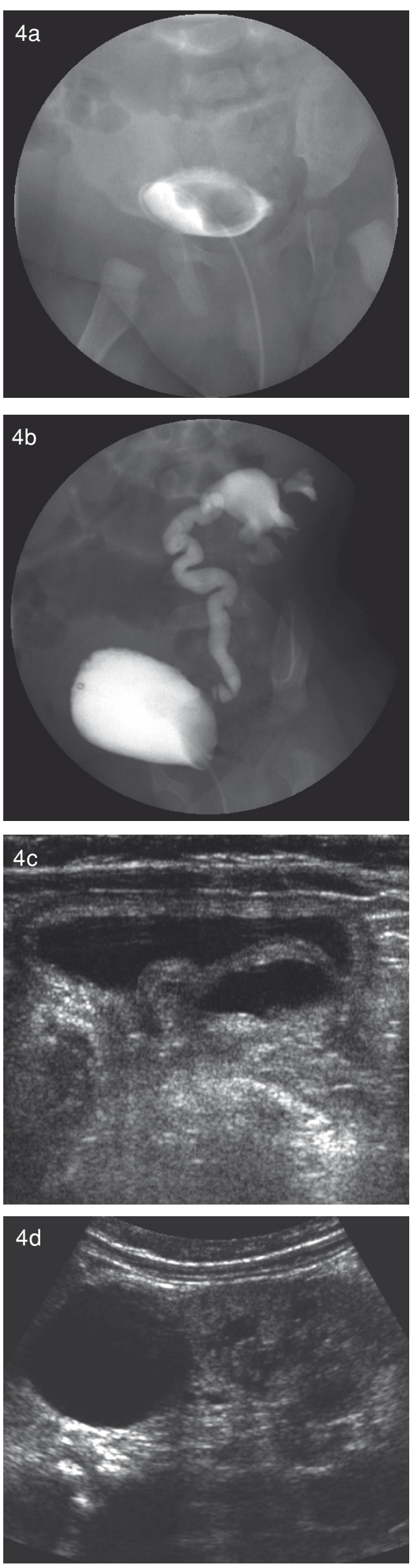

84
Figura $4 \boldsymbol{a}, \boldsymbol{b}, \boldsymbol{c}, \boldsymbol{d}$. Paciente con doble sistema excretor a izquierda y ureterocele. a) Imagen de uretrocistografía en etapa precoz que muestra la presencia de ureterocele como un defecto de llenado en el piso vesical. b) Imagen de uretrocistografía en etapa de llenado tardío que demuestra reflujo vesicoureteral grado 4 al sistema inferior izquierdo, visualizándose aún el defecto de llenado vesical correspondiente al ureterocele. c) Imagen de ultrasonido que muestra vejiga en corte transversal con presencia de ureterocele en concordancia con uretrocistografía. d) Imagen de ultrasonido que evidencia riñón izquierdo en corte longitudinal con presencia de doble sistema, marcada dilatación del sistema superior y atrofia parenquimatosa.

Es importante recordar que el ureterocele de inserción ectópica que origina obstrucción se visualiza mejor en fase precoz de llenado en la uretrocistografía miccional como un defecto, más evidente en proyecciones oblicuas, que en fase tardía puede ocultarse por la mayor cantidad de contraste existente e incluso evertirse por aumento de presión (Figura 5), pudiendo confundirse con divertículo(3).
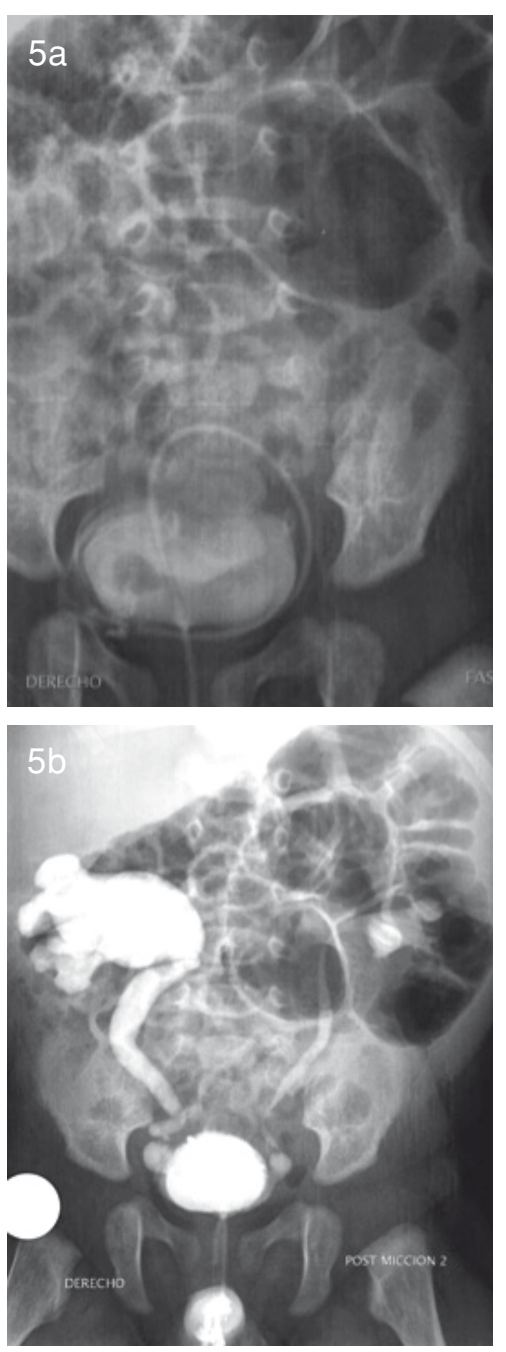

Figura 5a, b. Paciente con doble sistema pieloureteral y ureterocele bilateral. a) Imagen precoz de uretrocistografía miccional, en que se observa defecto de llenado bilateral en el piso vesical en relación a ureteroceles. b) Etapa postmiccional del mismo examen donde se observan ambos ureteroceles evertidos y reflujo vesicoureteral a ambos sistemas inferiores, mayor a derecha. 
El lirio caído también puede ser demostrado en UroRM y en menor proporción en UroTC realizados como parte de estudios de incontinencia urinaria, sospecha de anomalías congénitas o tumores. En ambos exámenes, en presencia de doble sistema pieloureteral con grupo superior dilatado, en fase de eliminación, es posible observar el signo de flor marchita por efecto de masa sobre el sistema inferior contrastado (Figura 6).
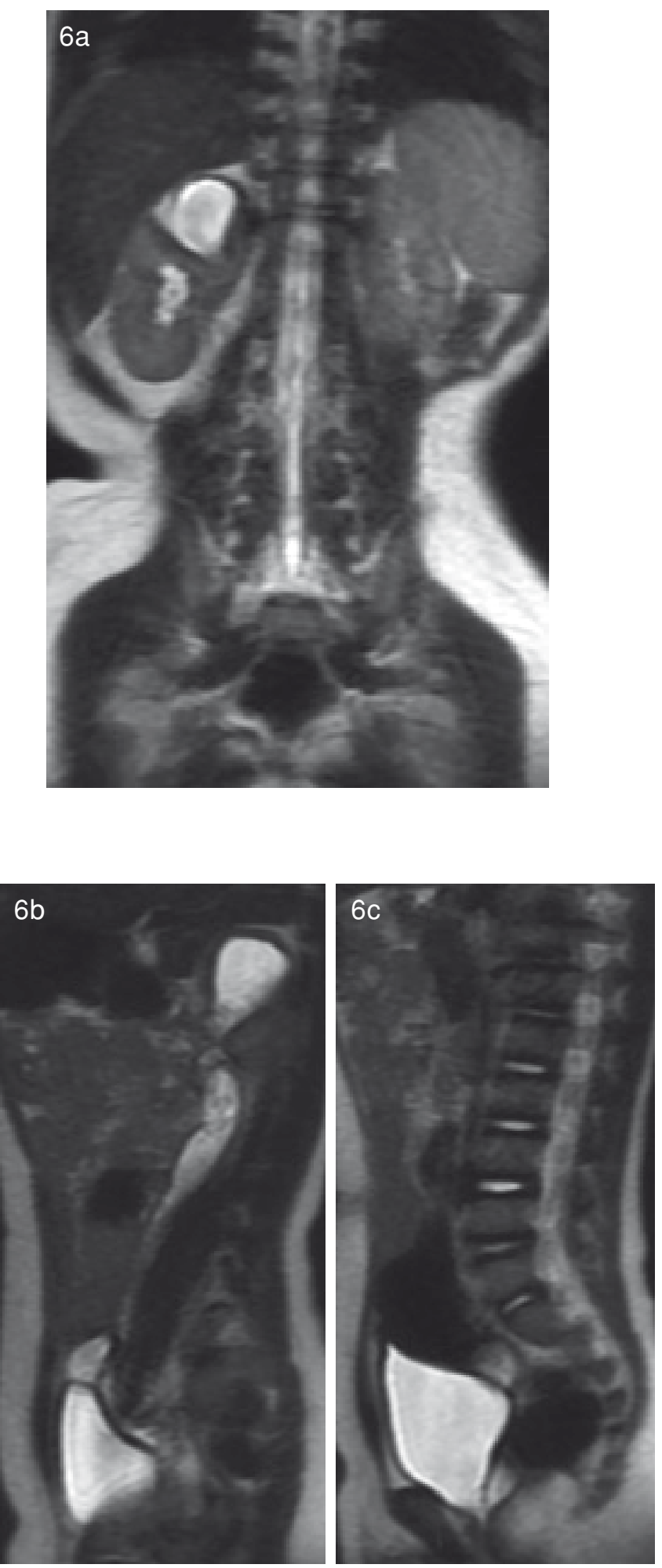
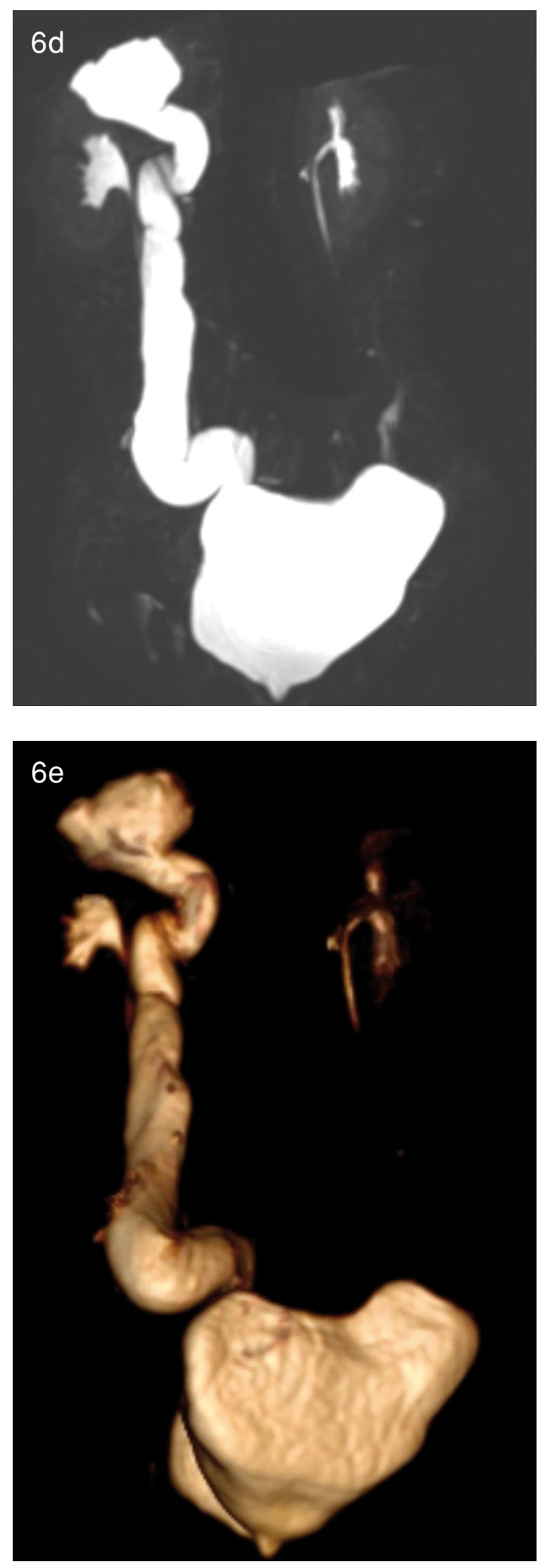

Figura $6 \boldsymbol{a}, \boldsymbol{b}, \boldsymbol{c}, \boldsymbol{d}, \boldsymbol{e}$. UroRM de paciente con doble sistema pieloureteral derecho, hidroureteronefrosis del sistema superior y uréter ectópico. $a, b$ y c) Imágenes en secuencia T2 HASTE coronal (a) y sagital (b y c) donde se observa doble sistema pieloureteral derecho con hidroureteronefrosis del sistema superior y demostración de la inserción ectópica del uréter. $d y$ e) Reconstrucciones volumétricas en que se representa la imagen de "lirio caído" por este método. Se identifica marcada dilatación y tortuosidad del sistema excretor superior derecho que determina efecto de masa sobre el sistema inferior no dilatado, con desplazamiento lateral e inferior de los cálices superiores del sistema inferior asociado a inserción ectópica vesical. El riñón izquierdo presenta configuración normal. 


\section{Diagnóstico Diferencial}

Una variante mucho menos frecuente de este mismo signo puede observarse en presencia de masas originadas en el espesor del parénquima renal o en el espacio perirrenal, tales como el neuroblastoma de origen adrenal, tumor de Wilms o absceso renal, que con su crecimiento comprimen y desplazan un sistema excretor único hacia inferior y lateral (Figura 7). Esta característica fue de mucha utilidad en la era previa a la tomografía computarizada y a la resonancia magnética, ya que permitía orientar el diagnóstico diferencial entre una masa originada dentro del espacio perirrenal y otra proveniente del aspecto extrarrenal ${ }^{(4,5)}$.

\section{Reseña histórica}

No existe claridad ni antecedente fidedigno en la literatura respecto de la fecha de descripción del signo del lirio caído. Las primeras publicaciones que se refieren a él datan de comienzos de la década de los '70 y su uso en la literatura se extendió en conjunto con el mayor uso de la pielografía de eliminación hacia fines de la misma década.

Su descripción disminuyó en forma significativa con el advenimiento de UroTC y UroRM, existiendo escasa evidencia en la literatura desde mediados de la década pasada.

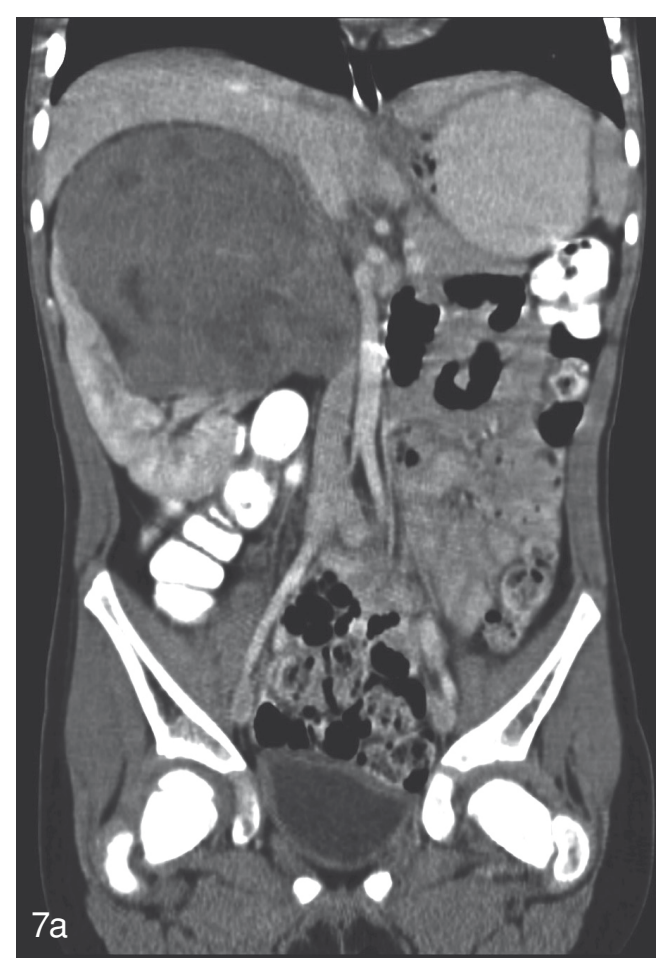

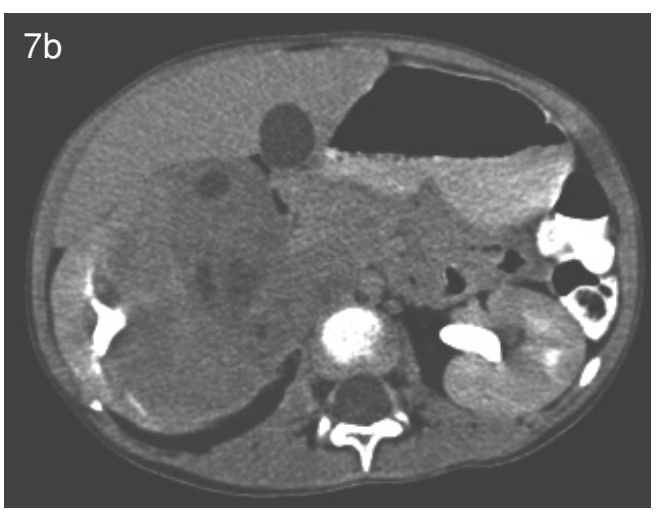

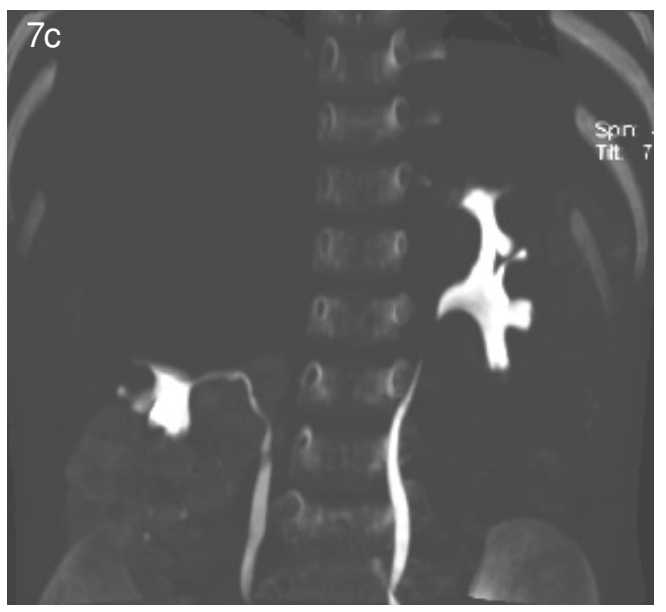

Figura 7a-c. Paciente de 5 años portador de tumor de Wilms a derecha en estudio con UroTC. a) Representación coronal en etapa venosa en que se observa extensa masa heterogénea originada en el aspecto superior del riñón derecho con significativo efecto de masa sobre el aspecto inferior. b) Representación axial en etapa de excreción que muestra alteración morfológica del riñón derecho debido a la masa, con sistema excretor comprimido y desplazado hacia lateral. c) Reconstrucción MIP en que se representan sistemas excretores de ambos riñones, de morfología normal a izquierda y con marcado desplazamiento inferior a derecha con la apariencia de "flor marchita".

\section{Discusión}

La duplicación del sistema excretor renal, erróneamente denominada duplicación renal, es la anomalía más común del tracto urinario y corresponde a una de las causas más frecuentes de aumento de tamaño renal y asimetría renal secundaria ${ }^{(3)}$. La incidencia de esta alteración es reportada en la literatura en aproximadamente un $0,8 \%$ de la población, más frecuentemente en la forma incompleta, siendo el sexo femenino más afectado que el masculino ${ }^{(6)}$. Esta anomalía del desarrollo es descubierta habitualmente en la niñez, aunque se describe también su diagnóstico como hallazgo incidental sin mayor relevancia en adultos e incluso como hallazgos en autopsias, en 
especial en sistemas duplicados incompletos. Puede asociarse a otras anomalías en el desarrollo del sistema excretor como son la displasia renal quística y el riñón en herradura(3).

La duplicación incompleta comprende cerca del $70 \%$ del total de estas alteraciones y se origina en la etapa embrionaria por una separación parcial de los uréteres en su proceso de unión al blastema metanéfrico, resultando en una pelvis renal doble, con fusión de los uréteres antes de la unión ureterovesical ${ }^{(3)}$. La duplicación del sistema excretor completa corresponde al $30 \%$ restante y se origina en la etapa embrionaria por una alteración a nivel de los conductos de Wolff, con el desarrollo de un uréter que se incorpora a la vejiga y asciende hasta insertarse en el aspecto inferior del blastema metanéfrico. En algunas oportunidades esta inserción vesical puede ser discretamente lateral a la ubicación normotópica, lo que determina un trayecto intramural más corto y, secundariamente, mayor incidencia de reflujo vesicoureteral ${ }^{(2,3)}$. Habitualmente el polo superior contiene menos cálices que el sistema inferior y su uréter, "unido" al conducto de Wolff, se inserta ectópicamente en la vejiga o en situación extravesical (uretra o vesículas seminales en niños y vagina en niñas) ${ }^{(3)}$. Esta inserción ectópica se puede asociar a orquiepididimitis a repetición en niños e incontinencia urinaria en niñas.

En la actualidad, el diagnóstico de duplicación del sistema excretor se realiza habitualmente a raíz de estudios de pacientes con antecedentes de dilatación del sistema urinario en etapa prenatal o en niños que se estudian por infección urinaria. De acuerdo a la regla de Weigert-Meyer, el uréter del polo superior se presenta con inserción ectópica medial e inferior a la inserción ortotópica en un $85 \%$ de las veces ${ }^{(7)}$, la mayoría asociado a ureterocele habitualmente obstructivo e hidroureteronefrosis del polo superior.
El uréter del polo inferior se complica con reflujo vesicoureteral y menos frecuentemente obstrucción pieloureteral.

\section{Conclusión}

El signo del lirio caído provee una representación gráfica y simple del proceso patológico que involucra la presencia de doble sistema pieloureteral completo, que frecuentemente incluye dilatación del sistema superior secundaria a ureterocele obstructivo de inserción ectópica, asociada a compresión y desplazamiento del sistema inferior.

\section{Agradecimientos}

Agradecemos al Dr. Víctor Dinamarca, Radiólogo de Clínica Las Condes, por su aporte a la edición del material gráfico.

\section{Bibliografía}

1. Dier R, Chen M, Zagoria R. Classic Signs in Uroradiology. Radiographics 2004; 24: S247-S280.

2. Callahan M. The Drooping Lily Sign. Radiology 2001 ; 219: 226-228.

3. Fernbach S, Feinstein K, Spencer K, Lindstrom C. Ureteral Duplications and its Complications. RadioGraphics 1997; 17: 109-127.

4. Westra S, Zaninovic A, Hall T, Kangarloo H, Boechat M. Imaging of the adrenal gland in children. RadioGraphics 1994; 14: 1323-1340.

5. David R, Lamki N, Fan S, Singleton E, Eftekhari F, Shirkhoda A, Kumar R, Madewell J. Radiographics 1989; 9: 859-882

6. Scipioni F, Cerchia E, Brandigi E, Meucci D, Pavone M, Messina M. Renal Duplex System in pediatric population. Journal of the Siena Academy of Scienses 2011; 3: 38-42

7. Friedland GW, Cunningham J. The elusive ectopic ureteroceles. AJR Am J Roentgenol 1972; 116: 792-81. 